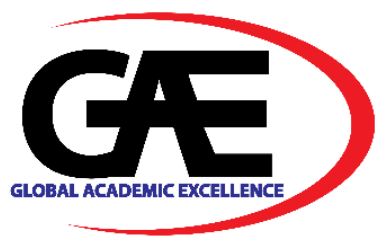

\title{
DIGITAL MEDIA LITERACY IN JORDAN: CHALLENGES AND DEVELOPMENT
}

\author{
Mohamad Ahmad Abdallah Abu Halka ${ }^{1}$, Shafizan Mohamed ${ }^{2 *}$
}

1 Department of Communication, Kulliyyah of Islamic Revealed Knowledge and Human Sciences, International Islamic University Malaysia

Email: m87.abuhalaqa@yahoo.com

2 Department of Communication, Kulliyyah of Islamic Revealed Knowledge and Human Sciences, International Islamic University Malaysia

Email: shafizan@iium.edu.my

* Corresponding Author

\section{Article Info:}

\section{Article history:}

Received date:01.10.2020

Revised date: 08.10.2020

Accepted date: 20.10 .2020

Published date: 06.12.2020

\section{To cite this document:}

Abu Halka, M. A. A., \& Mohamed, S. (2020). Digital Media Literacy in Jordan: Challenges and Development. International Journal of Law, Government and Communication, 5 (21), 34-44.

DOI: $10.35631 /$ IJLGC.521004.

This work is licensed under $\underline{\text { C BY } \text { B.0 }}$

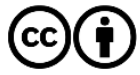

\section{Abstract:}

Digital media literacy refers to having the ability to use digital technologies to participate in and contribute to social, cultural, political, and economic life. It includes understanding the impact of recent technologies on society, understanding and having the ability to manage digital identities fittingly, and having the ability to find, organize, understand, evaluate, analyze and create digital information. While the level of digital media literacy in Jordan is still in its infancy, there is a positive move towards educating the Jordanian people about digital media. Recently the Jordanian government has developed a national executive plan for digital media literacy to develop community awareness and improve its capabilities in dealing with information and media sources during the Corona pandemic through the Ministry of Culture, Therefore, in this study, we will review the digital media literacy in Jordan and we will study the challenges and development of digital media literacy in Jordan.

\section{Keywords:}

Jordan, Digital Media Literacy, Arab, Education, Technology

\section{Introduction}

The concept of media literacy is not new but is definitely important among the researchers in the fields of education and the media (Potter, 2010). Several Western educational systems developed "media literacy" as a way to enable citizens to achieve informed interactions with media messages (Alhamadani, 2015). Along with technological advancements came the concept of digital media literacy that emerged as a broader and more comprehensive 


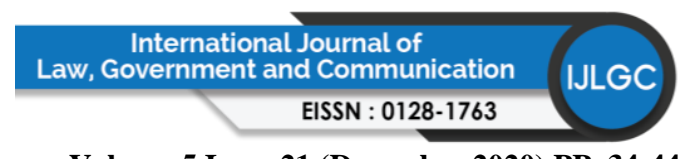

Volume 5 Issue 21 (December 2020) PP. 34-44 DOI 10.35631/IJLGC.521004 education form than the media literacy itself, although it was not a substitute for the concept. It was a concept that needed a broader understanding of basic skills; such as reading, writing, understanding and using modern technologies (Park \& Burford, 2013). Digital skills have now become necessary to equip community members with basic skills that will enable them to solve digital issues in their environment and the world at large.

Digital media literacy refers to having the ability to create and use technologies to participate in and contribute to social, cultural, political, and economic life. It includes understanding the impact of recent technologies on society, understanding and having the ability to manage digital identities fittingly, and having the ability to find, organize, understand, evaluate, analyze and create digital information (Hobbs, 2010). Digital literacy involves critically participating in technology and developing social awareness. However, a variety of things together with business agenda and cultural understandings will form how technology is employed to convey information (Assal, 2016). Having the ability to speak and represent data is entirely different in numerous contexts and to different audiences (for example, in visual, audio, or matter modes). This involves finding and choosing relevant information, critically evaluating and re-contextualizing data and is underpinned by an understanding of the cultural and social contexts during which this takes place. Digital literacy provides the citizens with the flexibility to require advantage of the wealth of recent and rising opportunities related to digital technologies while additionally remaining aware of what the different challenges technology will give. In short, digital literacy is the 'savvyness' that permits to participate in the digital realm meaningfully and safely.

In order for the desired benefit of digital media literacy to be realized, it is necessary to possess the skills that constitute the measurement tools for the effectiveness of digital media literacy for individuals. Digital media literacy skills are extensions of media literacy skills where the essence of the vocation and competence are to equip citizens the ability to search for the right information and using those information efficiently and positively. Individuals need skills to get a good understanding of how to create knowledge, express reality and engage in civic activities and social work (Hobbs, 2010).

When measuring media literacy competency, conventional definitions included skills of access, consumption and focuses on interpreting media messages (Auferheide, 1993; Hobbs 2001). Buckingham (2007) defines several of these constructs, explaining:

Access... includes the skills and competencies needed to locate media content, using the available technologies and associated software. ...Understand includes the ability to decode or interpret media, for example, through an awareness of formal and generic conventions, design features and rhetorical devices. It also involves knowledge of production processes, and of patterns of ownership and institutional control, and an ability to critique media, for example, in terms of the accuracy or reliability of their representations of the real world. Finally, create involves the ability to use the media to produce and communicate one's own messages, whether for purposes of self-expression or in order to influence or interact with others (p. 44).

However, with the inclusion of digital media, the skill of production or creation become significant. Media creation/production is the skill enabled by digital media in which the people are no longer passive audiences, they are also active content creators. Therefore, 


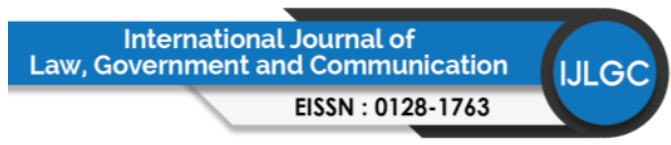

Volume 5 Issue 21 (December 2020) PP. 34-44 DOI 10.35631/IJLGC.521004

media creation is the main characteristic that distinguishes digital literacy from media literacy (Park, 2012). In 2011, UNESCO concluded that the most common digital literacy abilities are awareness, access, evaluation and creation. This statement is agreed by scholars who have considered these skills as measurements of digital media literacy competency (Assal, 2016; Fedorove, 2008; Hallaq, 2016).

Jordanians are very much exposed to different types of media. With a population of 10 million people, there are thirty-eight TV channels, thirty-nine radio stations, and about thirty newspapers daily and weekly (Media Commission, 2019). According to the Jordanian Department of Statistics (2017), social media usage has reached 93.5\%. With this widespread media usage particularly online media, the Jordanian audiences are not solely exposed to smart data, they are conjointly subjected to the risks of harmful usage and content. This might embody violence, extremism, cultural invasion, and incorrect conventional pictures regarding status, race, or gender, additionally to the industrial nature of media messages (Darweesh, 2006).

The level of digital media literacy in Jordan has been developed in recent years, there is a positive move towards educating the Jordanian people about digital media (Ashdiefat \& Khasawneh, 2012; Melki, 2015). Jordan Media Institute (JMI) is probably the country's biggest proponent for media literacy. JMI is a freelance media institute that aims to enhance the output of Jordanian media and to promote the name and image of the media profession domestically and regionally by establishing medium that helps to circularize the ideas of media literacy (JMI, 2018). In this paper, we will review the digital media literacy in Jordan and we will describe the challenges and development of digital media literacy in Jordan. In section 2 we will explore the history of digital media literacy in Arab world and Jordan. In section 3 we will explicate the challenges of digital media literacy in Jordan. In section 4 we will review the recent developments of digital media literacy in Jordan. Finally, in section 5 we will provide the conclusion and recommendation.

\section{Methodology}

This paper is conceptual in nature. However the historical analysis provided was done through a careful reading of literatures on media literacy in the Arab world generally and in Jordan more specifically. This study is also part of the first author's PhD thesis in which he had conducted multiple interviews with relevant parties such as media experts and members of the Jordan Media Institute (JMI). Therefore the discussion provided is also based on a deliberate input from experts in the area who are very familiar with the media and education landscape in Jordan.

\section{History of Digital Media Literacy in The Arab World and Jordan}

The Arab world neglected media literacy for a long time, which led to negative consequences that exacerbated the seriousness of political and economic disturbances. Abu-Fadil (2016) described the reason for neglecting digital media literacy to the Arab higher education systems which have been suffered from the absence of facilities and equipment that require digital literacy. Moreover, the individual academic initiatives that called for media literacy in Arab universities have been met with opposition and lack of support from traditional academics, while most of these educational systems do not realize the importance of Media and digital literacy (Melki and Maaliki, 2016). 


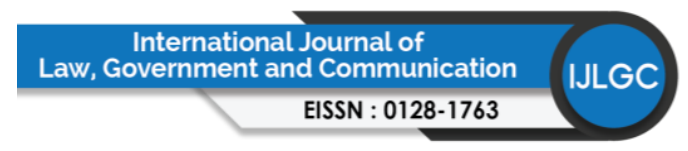

Volume 5 Issue 21 (December 2020) PP. 34-44 DOI 10.35631/IJLGC.521004

Furthermore, media literacy is at the bottom of the list of Arab priorities, as it reflects the state of the media itself, which is a tool of power and indicates a lack of respect for the press and its lack of prestige, and this is reflected in the degree of credibility, thus it serves the interest of the ruling elites (Saleh, 2009). However, digital media literacy has been included in the curricula of a number of Egyptian universities since 2005, in addition to WeChat organizing workshops for final year students at the Faculty of Mass Communication at Cairo University on media literacy (Tayie, 2016). In Palestine, the concept of media literacy was a new concept at the level of civil society, so efforts were limited to some initiatives, activities and projects that have increased since 2009 (Nuseibeh and Abu Arqoub, 2016).

At the beginning of the new millennium, interest in digital media literacy began in Jordan through some official Jordanian initiatives to develop digital literacy, such as the Ministry of Education training teachers to use computers by obtaining the International Computer Driving License (ICDL) program, as well as the (INTEL Education for the Future program), hoping to provide teachers With computer skills and employing them in the educational process and using them in obtaining media content that affects digital media literacy (Olaimat, 2013). The Ministry of Education, in cooperation with several bodies, including the Center for the Protection and Freedom of Journalists, launched the (Education Through Journalism) program, which was considered the first training in media literacy, in which schools invest on daily newspapers to teach many educational materials such as history, geography, science, reading, civic education, creation and expression to a group of school students. The exercises and activities were are carried out inside the classroom at the rate of one session per week to enable students to keep pace with the developments of the age and the knowledge revolution and to create a spirit of dialogue and interaction with various community issues. With the aim of training Jordanian youth, providing them with knowledge and skills to deal with the media, facing illiteracy in information and communication technology, and promoting freedom of expression, the Jordanian National Committee for Education, Culture and Science, in cooperation with the UNESCO Office in Amman and the Arab Women Media Center, implemented an exploratory project entitled (Introducing the concept of media literacy in Jordanian schools ) With funding from the Swedish government in 2013 (Assal, 2016).

The United Nations Alliance of Civilizations (UNAOC) and Google, in cooperation with the World Bank Institute, held a training workshop in 2013 entitled Digital Tools for News Gathering and Cross-Cultural Reporting at the Jordan Media Institute in Amman (UNAOC, 2013, Durra, 2016), which was considered a step towards Introducing the concept of digital literacy in Jordan

The International Center for Journalists organized a training course at the Jordan Media Institute in 2013 on the use of electronic tools in public service issues, which dealt with preparing press reports, building electronic news websites, media ethics in the electronic age and social media, and how to employ This is in its coverage of issues related to public services with the participation of media professionals and journalists from several Arab countries (Jordan Media Institute, 2013).

Accordingly, it appears that the stages by which the adoption of the digital media literacy concept by Jordanian official institutes was not part of a clear process and policy based on a strategy for developing this concept and benefiting from it while not being adopted by the 


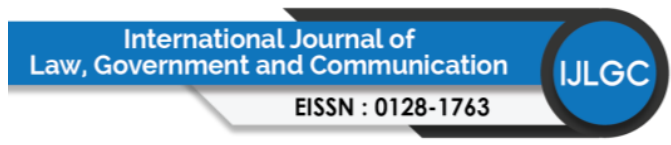

Volume 5 Issue 21 (December 2020) PP. 34-44 DOI 10.35631/IJLGC.521004 Jordanian government and placing it among its priorities during the period before 2014. They were just initiatives by international institutions and Jordanian civil society institutions.

\section{Challenges That Face the Implementation of Digital Media Literacy in Jordan}

Recently, the concept of digital literacy has entered, which is broader and more comprehensive than media literacy, but it is not a substitute for it. Rather, it needs a broader awareness of basic skills such as reading, writing, understanding, and accessing new technologies (Park, 2012)

The state of digital media literacy in the Arab world, including Jordan, is weak, as interest in it comes at the bottom of the list of priorities for Arab countries, noting that it reflects the state of media itself (Saleh, 2009). On other words, the digital media literacy in the Arab world is still in the initial foundational stages (Melki, 2013).

The challenges facing digital media literacy are summarized by several reasons, including political, economic, and social (culture). For instance, The Arab world, including Jordan, neglected digital media literacy for a long time, which led to negative consequences that exacerbated the seriousness of political and economic unrest (Abu-Fadil, 2016). Many obstacles stand in front of the spread of media and digital literacy, such as the structure of the media, which in turn does not provide the opportunity for a sufficient number of voices to participate, and the various political and social situations restrict the flow and availability of information, in addition to the imbalance in the ability of individuals to communicate their opinions and voices (Assal, 2016). Among the factors affecting Digital Media Literacy in Jordan are the economic weakness and the high costs of production and publishing with the lack of financial support provided for the development of human resources and education, on which media literacy depends on (Saleh, 2009).

Moreover, Arab higher education systems suffer from the absence of facilities and equipment that require digital literacy, and individual academic initiatives that called for media literacy in Arab universities were met with opposition and lack of support from traditional academics, while most of these educational systems do not realize the importance of digital media literacy. In addition, it does not feel that it should be integrated into the school curriculum (Melki and Maaliki, 2016).

Although Jordanian youth have the skill and intelligence to use digital technologies, they mostly still unaware of the dangers of social media, and that most of these young people are ignorant of the Internet threat such as privacy threat. Despite their extensive use of social media, they cannot be described as fruitful producers. Consequently, Jordanian youth who used the Internet have suffered from the lack of effective application of blogs. Like young bloggers in many other developing countries (Mohamed, 2017) they predominantly blogged about entertainment and light news indicating the lack of their awareness regarding the power of these means in influencing social and political views (Melki, 2015). Despite the challenges, the application of digital media literacy in Jordan y has witnessed remarkable developments during the recent period and this will be discussed in the next section.

\section{Development of Digital Media Literacy in Jordan}

Recently, digital media literacy has been developed remarkably, as these developments were represented in several stages, the beginning of which was in 2010, when the Jordanian 


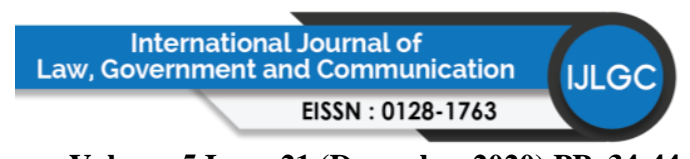

Volume 5 Issue 21 (December 2020) PP. 34-44 DOI 10.35631/IJLGC.521004 academics became aware and interested in the concept of digital media literacy and they pressured the politicians to pay closer attention to this concept. In response, new researches and studies were published to delineate and discuss the concept of digital media literacy. Jordanian academics were focused on identifying the tools that individuals must possess to qualify them to interact with the media in a positive way. For instance, Ashdiefat \& Khasawneh, (2012) studied the extent to which Jordanian school students possess the concept of digital media literacy, which gave a simplified picture of the scene., Assal (2016) studied the extent of parents' awareness of digital media literacy and the importance of this concept to them because of its potential.

Subsequently, the UNESCO Amman office launched a project to support the media in Jordan, with funding from the European Union, starting from 2014 until 2017, and the project included developing media education capabilities (UNESCO, 2014). In addition to this, the Jordan Media Institute, in partnership with UNESCO, launched the Media and Information Education Project in Jordan in May 2016, which comes within the main project to support the media in Jordan, which UNESCO began implementing in 2014 with funding from the European Union (Jordan Media Institute, 2016).

The project came in two phases; the first included the institute's development of a Jordanian public policy paper in the field of media and information education in educational institutions. The paper analyzed the universities curricula and the extent to which they contain media literacy concepts. The paper suggested a strategy that will work to introduce these concepts, while the second phase introduced the concept of Media education in educational curricula within the framework of cooperation with relevant parties that included the Ministry of Education and the Jordanian universities. Among others, this Initiative wanted to train male and female teachers on media and information literacy skills so that they can transfer the necessary knowledge to students of grades seven, eight and nine in a number of schools (Jordan Media Institute, 2016)

In 2016, the Jordan Media Institute launched the Jordanian Media Credibility Observatory (Akeed) with an important role in providing recipients with digital media literacy skills and enhancing their presence among individuals The observatory contributed by verifying and monitoring media content published in the Jordanian media to enhance the quality of information by stressing on the elements of objectivity, credibility and accuracy. It also proposed for awareness be imparted to Jordanians so that they can verify those elements in the messages they receive. (Akeed.jo, 2016)

The objectives of the observatory reinforced the objectives of the existence of digital media literacy by protecting individuals and groups from the negative and unethical influences that may exist in the media content. It also enhances the accessibility skill of the recipient by assigning the human right to knowledge by being able to achieve objectivity and separate between news and advertisements, between facts and speculation and the separation of information, facts on the one hand, and imagination and emotions on the other hand, and it also contributes to providing students and journalists with the tools necessary to enhance future media education programs (Durra, 2016). In 2018, the Jordanian government adopted the policy paper on digital media literacy that was drafted by the Jordan Media Institute in partnership with the European Union and UNESCO. Followed by training for school and 


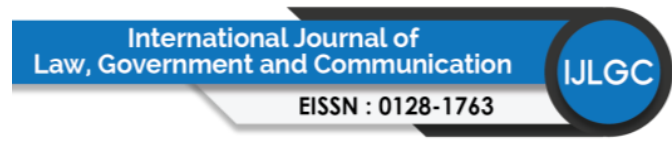

Volume 5 Issue 21 (December 2020) PP. 34-44

DOI 10.35631/IJLGC.521004

university students on digital media literacy concepts through several training programs funded by external donors and most notably, UNESCO.

Most recently, while being affected by the global Corona pandemic, the government has developed, through the Ministry of Culture, an executive plan for "the National Initiative for the Promotion of Media and Information literacy for the years (2020-2023)". Because of the dire need to depend on digital technologies caused by the pandemic, the Ministryn developed a work program to improve society's ability to deal with information sources, news, and digital media tools. The strategic objective of the plan is to integrate media and informational literacy concepts and skills into the Jordanian educational system, publish them in schools and universities, incorporate the activities of cultural and youth institutions and civil society institutions, and spread awareness of them through the media and in the public sphere.

According to the general policy paper presented by the Jordanian government, these are the main reasons why digital media literacy is a societal necessity in Jordan:

\section{First: Knowledge Transfer Tool}

Digital Media literacy is a tool for developing and reforming education and a tool for transferring knowledge through technology: Today, the use of information and communication technology (ICT) is the most prominent and important tool in increasing access to education, raising the quality of education using advanced teaching and learning methods, improving learning outcomes, and reforming educational systems management. (UNESCO, 2018)

\section{Second: Digital Media Literacy is Considered A Means of Social Integration.}

It can be pointed out that digital media literacy is an effective tool that improves opportunities for social harmony and opportunities for societal understanding and understanding, as the press and radio were used in early periods in the reproduction of more integrated societies that agreed on common large goals without exceeding the value of diversity, for example as happened in the Malaysia (Mohamed, 2018). Contemporary Jordanian society is now very diverse mainly due to the modern formation of society and the emergence of the state. The waves of refugees that have not stopped over the course of six decades have increased society diversification, and although the state and society have been able to digest this diversity and reproduce it in many stations, Jordan still needs more indepth efforts in support of social integration processes, bridging gaps and some aspects of fragility. Thus communication technology can assist Jordanians to become more integrated by sharing and expressing through digital and social media.

\section{Third: Bridging the Political and Social Participation Gap}

Learning the skills of sharing information and producing and sharing media content is the basic feature of the communication and information revolution, and the events and transformations that the world is witnessing in the last decade confirm that this pattern of participation is contributing to determining the level, content and size of participation that individuals practice in various aspects of life, foremost of which is social and political participation. As is well known, participation is the solid foundation for development and modernization when the responsibility base expands. The quality of dealing with information and news improves opportunities for political participation, whether electoral participation or participation in public affairs, in addition to the role of digital media education in improving 


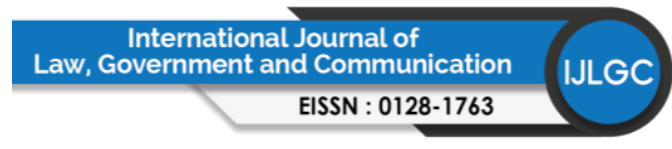

Volume 5 Issue 21 (December 2020) PP. 34-44

DOI 10.35631/IJLGC.521004

citizens' ability to accept equality and seek it, specifically between gender, the empowerment of women, and strengthening the participation of special groups.

Digital media education today defines this way in which more generations can be brought up ready for positive and productive participation thanks to the cognitive and cultural cultivation of participation based on evaluation, selection of ideas and critical thinking. Jordan suffers from a multi-faceted participation crisis, whether in the political or socio-economic dimensions, evidenced by the weak electoral participation that did not exceed $37 \%$ in the 2016 Eighteenth Council elections. The gender gap in women's participation rates appears more obvious and embarrassing, as the rate of Jordanian women's economic participation in the labor market is still low and does not exceed 14\%, compared with $30 \%$ at the Arab level and 50\% at the global level, and weak and distorted participation extends to other sectors such as work. Volunteering and non-profit work, as this sector only accounts for $1.5 \%$, compared to 5.5\% of the global average (Jordanian Department of Statistics, 2017).

\section{Fourth: Rationalize Societal Culture in Confronting Extremism and Hate Speech}

Digital media has become one of the open sources today that allows participation for young people, young and old, and at a time when the mass media and new information sources along with the traditional media have come to dominate a wide area of individuals' times, they have been transformed by the political conflict in the Middle East and North Africa regions. And others, to effective platforms for spreading extremism and spreading hate speech, as many reports indicate that these means have become a trap for hunting young people by terrorist organizations, in addition to their role in spreading extremist ideas and creating followers for them.

Therefore, Jordanian youth find themselves in the midst of a torrent of information flow, and at a time when traditional educational institutions deny them expression, and traditional media do not give them real attention, young people find the new media of expression available on digital media, specifically social media, an escape from exclusion and marginalization. Its ability does not depend on the inexpensive means it provides and without direct censorship, but rather allows anonymity, which has opened the way to anomalous expressions such as expressions of cultural and verbal violence and hates speech on the one hand and extremist religious and political discourse.

Digital media literacy contributes to a large extent to developing the capabilities of individuals to examine, evaluate, accept or reject media messages, as what media literacy provides makes young people and new youths more immune to political and ideological propaganda, at the forefront of which is the distinction between messages with political and ideological goals and news. Impartial information makes the recipients more alert and aware of extremist messages.

In order to benefit from the integration of digital media education, a plan had to be developed Implementation of the national initiative that according to the Minister of Culture (Twissi, 2020) includes four areas which are the 1) Schools, 2) Univesrities, 3) youth and cultural institutions and, $\$ 0$ civil society and the public sphere in cities. 


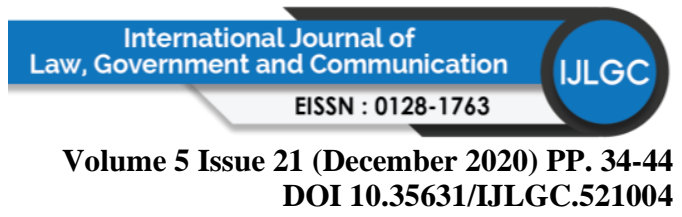

\section{Area 1: Schools}

It includes training activities and access to about $90 \%$ of the Ministry of Education schools in the Kingdom's governorates, within 42 directorates of education and training, 3000 male and female teachers, and the introduction of digital media literacy concepts and skills to the educational curricula in the concerned classes and ensuring their sustainability, reviewing them, and developing student activities guides specialized in digital media education. For students of basic education and establishing student clubs specialized in this field.

\section{Area 2: Universities}

It aims to build the capacities of a group of faculty members in Jordanian universities, and to invite universities to offer specialized courses in digital media education and the establishment of university student clubs and parallel activities in the field of media and information education. This goal includes establishing 30 student clubs in the field of media and informational education and working with teacher training colleges to offer educational programs in media and informatics education.

\section{Area 3: Youth and Cultural Institutions}

It aims to train and build capacity for members of the youth centers of the Ministry of Youth and the cultural bodies of the Ministry of Culture in all parts of the Kingdom, and to enable a group of youth centers and young women and cultural bodies to develop units for digital media awareness and the production of media and information content.

\section{Area 4: Civil Society and The Public Sphere in Cities}

The plan aims to administer sub-grants targeting a group of civil society institutions interested in launching new and innovative initiatives in the fields of media and information education under the supervision of the Ministry of Culture and the Office of the Minister of State for Media Affairs, and the implementation of awareness campaigns to spread the concepts of media education And informatics through a group of public service media, and the creation of a digital platform for free education and training.

\section{Conclusion and Recommendations}

In short, we have explicated the challenges and development of digital media literacy in Jordan. The sequence of entering the concept of digital media literacy Jordan was reviewed, and the challenges that faced Jordan to apply the concepts of digital media literacy were presented. For instance, the digital media literacy programs that were implemented were financed and supported by external institutions in addition to the challenge of cultural awareness among young people in dealing with digital media correctly and in productive way was constituted as an obstacle for the digital media literacy in Jordan. The political challenges also clearly affected the progress of the development of digital media literacy through the various media outlets that represent the decision-makers opinions and control what is presented. As for recent years, specifically, since 2018, government interest in the concept of digital media literacy became apparent through practical steps that were manifested by the introduction of training programs in schools and universities and the development of a strategic plan for digital media literacy 2020-2023.

In response to the analyses provided, the authors recommend for the Jordanian authorities to further enhance their digital media initiatives by adopting the following: 


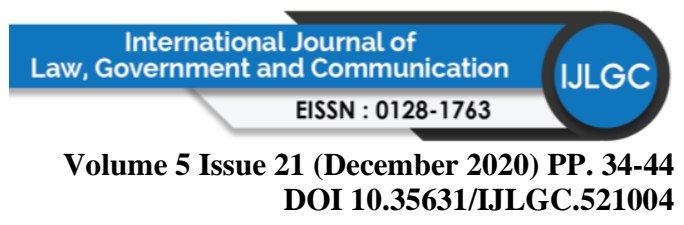

1. Establishing a clear digital media literacy curriculum in schools and universities as a separate and independent curriculum to be taught in theoretical and practical way, and to be designed locally in Jordan to comply with local culture and customs.

2. The teachers and trainers of digital media literacy must be specialized in digital media to provide content related to digital media literacy in a professional and beneficial way.

3. Disseminating media messages through various media outlets explaining the importance of digital media literacy Which includes understanding media, contemporary communication, news literacy, information literacy, digital citizenship, to create a state of public trust and cognitive immunization in the face of rumors and misinformation, and this perspective is committed to promoting the principles of human rights, freedom of expression and gender justice.

The paper concludes by confirming that the potential of digital media literacy in Jordan is very positive. If the government and the relevant authorities maintain their commitment to realize the strategic plans that are already in place, it won't be long before Jordanians become savvy technology users, and Jordan will become the leader on digital media literacy especially in the Arab world. The authors also propose for more studies to be conducted to understand how digital media literacy can be made more effective and relevant when it is studied within the context of a particular culture and socio-political backgrounds. Such studies can provide more avenues for comparing the applicability of different digital media literacy methods and modules.

\section{References}

Abu-Fadil, M., Torrent, J., \& Grizzle, A. (2016). Opportunities for media and information literacy in the Middle East and North Africa. The international clearinghouse on children, youth and media.

Alhamadani, B. (2015). Altarbyah alelamyah wa maho al omyyah alraqameyah. Amman: Dar Wael publisher.

Ashdiefat, A., \& Khasawneh, K. (2012). The Factors Influencing Media Education in Private Schools in Jordan from Students' Perspective. Specialized educational international journal, 1(6):274-287

Assal, H. (2016). Parents' knowledge of media and digital literacy in the Jordanian society. (Unpublished master's thesis). Jordan university, Amman.

Buckingham, D. (2007). Digital Media Literacies: rethinking media education in the age of the Internet. Research in comparative and international education, 2(1), 43-55.

Darweesh, A. R. (2006). Moqademah fe elm aletisal. Damietta: Nancy library.

Department of Statistics. (2017). Retrieved from http://dosweb.dos.gov.jo/population/

Fedorov, A. (2008). Media education around the world: Brief history. Acta Didactica Napocensia, 1(2).

Hallaq, T. (2016). Evaluating online media literacy in higher education: validity and reliability of the Digital Online Media Literacy Assessment (DOMLA). Journal of Media Literacy Education, 8(1), 62-84.

Hobbs, R. (2010). Digital and Media Literacy: A Plan of Action. A White Paper on the Digital and Media Literacy Recommendations of the Knight Commission on the Information Needs of Communities in a Democracy. 


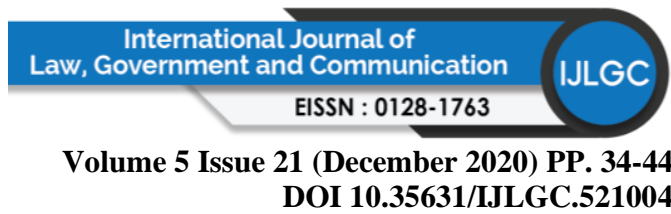

Jordan Media Institute. (2013), JMI Students participate in the Digital Media Literacy Academy. Retrieved from https://www.jmi.edu.jo/en/jmi-students-participate-digitalmedia-literacy-academy

Jordan Media Institute. (2016). JMI Students Take Part in Course at Media and Digital Literacy Academy in Beirut. Retrieved from http://www.jmi.edu.jo/en/details/4417/JMI-Students-Take-Part-in-Course-at-MediaandDigital-Literacy-Academy-in-Beirut

Jordan Media Institute. (2018), About Jordan Media Institute. Retrieved from https://www.jmi.edu.jo/en/About-JMI

Media commission. (2019). Licensed media in jordan. Retrieved from http://www.mc.gov.jo/Pages/viewpage?pageID=34

Melki, J. P. (2013). Sowing the Seeds of Digital and Media Literacy in Lebanon and the Arab World. Media Literacy Education in Action: Theoretical and pedagogical perspectives. BS De Abreu and P. Mihailidis (Eds.). Routledge, New York, USA, 7786.

Melki, J. P. (2015). Guiding Digital and Media Literacy Development in Arab Curricula through Understanding Media Uses of Arab Youth. Journal of Media Literacy Education, 6(3), 14-28.

Melki, J., \& Maaliki, L. (2016). Helping Arab digital and media literacy blossom: three years of the Media and Digital Literacy Academy of Beirut (MDLAB). University of Gothenburg, Sweden: The International Clearinghouse on Children Youth and Media.

Mohamed, S. (2017). Blogging and Citizenship: The Malaysian experience. Journal of Advanced Research in Social and Behavioural Sciences , 9 (1),102-114

Mohamed, S. (2018). The Islamization of the Malaysian media: a complex interaction of religion, class and commercialization. Intellectual Discourse , 26 (2) pp.635-658

Nuseibeh, L., \& Arqoub, M. A. 5. An Overview from the Occupied Palestinian Territories. Opportunities for Media and Information Literacy in the Middle East and North Africa, 55.

Olimat, A. (2013). waqee istikhdam mualemi alolom lilmustahdathat altiqnologyah fe tadresehim be muhafathat almafraq. Almanarah for Research and Study jornal, 20(1), 465-498.

Park, S. (2012). Dimensions of digital media literacy and the relationship with social exclusion. Media International Australia, 142(1), 87-100.

Park, S., \& Burford, S. (2013). A longitudinal study on the uses of mobile tablet devices and changes in digital media literacy of young adults. Educational Media International, 50(4), 266-280.

Potter, W. J. (2010). The state of media literacy. Journal of broadcasting \& electronic media, 54(4), 675-696.

Saleh, I. (2009). 5. Media literacy in MENA: moving beyond the vicious cycle of oxymora. Comunicar, 16(32), S155-S155.

Samy Tayie, S. (2019). News literacy for a responsible online news experience against harmful messages: implications for political engagement of Egyptian and Spanish youth.

The United Nations Educational, Scientific and Cultural Organization (UNESCO). (2014). Support to Media in Jordan. Retrieved from http://www.unesco.org/new/en/amman/projects/communication-andinformation/supportto-media-in-jordan/ 